\title{
Axial Spondyloarthritis after bariatric surgery: a 7-year retrospective analysis
}

\author{
Thauana Luiza de Oliveira ${ }^{*^{*}} \mathbb{D}$, Hilton Telles Libanori ${ }^{2}$ and Marcelo M. Pinheiro ${ }^{1}$
}

\begin{abstract}
Background: In recent decades, obesity has become a public health problem in many countries. The objective of this study was to evaluate the main joint and extra-articular manifestations related to spondyloarthritis (SpA) after bariatric surgery (BS) in a retrospective cohort.

Methods: Demographic, clinical, laboratory and imaging data from nine patients whose SpA symptoms started after a BS have been described. Modified New York (mNY) criteria for ankylosing spondylitis (AS) and the Assessment of Spondyloarthritis International Society (ASAS) criteria for axial (ax-SpA) and peripheral (p-SpA) spondyloarthritis were applied.

Results: The mean weight reduction after BS was $49.3 \pm 21.9 \mathrm{~kg}$. The BS techniques were Roux-en- $Y$ gastric bypass $(n=8 ; 88.9 \%)$ and biliopancreatic diversion with duodenal switch $(n=1 ; 11.1 \%)$. Four (44.4\%) patients had no axial or peripheral pain complaints before BS, while the other four (44.4\%) had sporadic non-inflammatory back pain that had been attributed to obesity. One patient (11.1\%) had persistent chronic back pain. In all nine cases, patients reported back pain onset or pattern (intensity or night pain) change after BS (mean time 14.7 \pm 18 months). In addition, 8 of them (88.9\%) were human leukocyte antigen (HLA)-B27 positive. All nine patients could be classified according to ASAS criteria as ax-SpA and five (55.6\%) patients were classified as AS, according to the mNY criteria.

Conclusion: Our data highlight a temporal link between SpA onset symptoms and the BS, suggesting a possible causal plausibility between the two events.
\end{abstract}

Keywords: Spondyloarthritis, Bariatric surgery, HLA-B27

\section{Key message}

1- Spondyloarthritis could arise after surgical interventions for the treatment of obesity.

2- Microbiota changes may play a key role as trigger in this setting and Human leukocyte antigen (HLA)-B27 could be considered as screening tool before BS.

\section{Background}

In recent decades, obesity has become a public health problem in many Western countries related to lifestyle changes, including higher low-nutritional value and high-calorie foods intake, as well as no regular physical activity. These aspects partly explain the increase of

* Correspondence: thauanareumato@gmail.com

${ }^{1}$ Rheumatology Division, Spondyloarthritis Section, Universidade Federal de São Paulo, Rua Leandro Dupré, 204, Conjunto 74, Vila Clementino, São Paulo, SP CEP 04025-010, Brazil

Full list of author information is available at the end of the article bariatric surgeries (BS) rate for treating of morbid obese patients and overweight individuals with comorbidities, because it has provided global benefits, especially for quality of life, self-esteem, control of peripheral insulin resistance and metabolic syndrome. Moreover, it is considered the most effective treatment for obesity, since the non-pharmacological approach, based on lifestyle changes and psychotherapeutic support, as well as drug therapy, has a high recurrence rate of weight gain $[1,2]$.

BS may cause several neuroendocrine changes, especially those related to the leptin axis, ghrelin, glucagonlike peptide-1 (GLP-1) and other incretins, promoting an early satiety state, weight loss, and better glucose control. However, many complications can occur. In the short-term, these include infections, bleeding, and pulmonary thromboembolism; and in the long-term, they include nutritional deficiencies, anastomotic stenosis, osteoporosis, gallstones and kidney stones [2].

(c) The Author(s). 2019 Open Access This article is distributed under the terms of the Creative Commons Attribution 4.0 International License (http://creativecommons.org/licenses/by/4.0/), which permits unrestricted use, distribution, and reproduction in any medium, provided you give appropriate credit to the original author(s) and the source, provide a link to the Creative Commons license, and indicate if changes were made. The Creative Commons Public Domain Dedication waiver (http://creativecommons.org/publicdomain/zero/1.0/) applies to the data made available in this article, unless otherwise stated. 
From an immunological perspective, some immunemediated manifestations related to intestinal bypass (BP) surgeries have been described. These are mainly associated with jejunoileal BP, including arthritis, immune complex glomerulonephritis, cutaneous vasculitis, pericarditis, Raynaud's phenomenon, psoriasis and pyoderma gangrenosum [3-5]. The Bowel-associated DermatosisArthritis Syndrome (BADAS), described in 1979 by Dicken and Seehafer, is one of the manifestations better associated with intestinal BP [6, 7]. It is characterized by recurrent episodes of fever, polyarthralgia or polyarthritis associated with skin lesions. It has also been described after other types of surgery and intestinal anastomoses, such as Billroth II gastrectomy, biliopancreatic diversion, ileocolic BP, appendectomy, and bariatric surgery with more recent surgical techniques $[8,9]$.

The main rheumatic manifestation associated with the jejunoileal BP is arthritis, commonly episodic, migratory, and polyarticular, with a predominantly self-limited course, but sometimes with a chronic evolution similar to rheumatoid arthritis $[10,11]$. The axial involvement is less frequent and may be associated with the HLA-B27 positivity $[12,13]$. Conversely, obese patients with rheumatoid arthritis or systemic lupus erythematosus may benefit from BS since it contributes to better disease control and dose reduction of immunosuppressants $[14,15]$.

The pathophysiology of these immune-mediated manifestations is unknown, although both innate and adaptive immunity are involved. Among the most accepted theories, the intestinal microbiome changes after surgery stand out, such as bacterial overgrowth due to the increase of $\mathrm{pH}$, and the blind loop syndrome. Altogether they could cause alterations of intestinal permeability and bacterial translocation, which would work as a trigger for the intestinal and systemic immune activation through molecular mimicry between peptides from gram-negative bacteria and structures of the synovial membrane and synovio-entheseal complex [16]. Some histopathological studies of the intestinal blind loop from patients with BADAS demonstrated a non-specific chronic inflammatory response [3].

The objective of this study was to describe patients who underwent BS before onset of spondyloarthritis (SpA) symptoms.

\section{Methods}

Among 429 patients from the Spondyloarthritis database from the Rheumatology Division at the Federal University of São Paulo, nine (2.1\%) had SpA-onset symptoms after BS from 2010 to 2016. These patients denied any inflammatory back pain (IBP), enthesitis, dactilitis, arthritis or extra-articular manifestations such as uveitis, colitis or psoriasis before being submitted to BS.
Demographic, clinical, laboratory and imaging data from these patients, including plain pelvic radiograph and sacroiliac joint (SIJ) and spine magnetic resonance imaging (MRI), when applicable, are shown. Furthermore, the modified New York (mNY) criteria for ankylosing spondylitis (AS) and the Assessment of Spondyloarthritis International Society (ASAS) criteria for axial (ax-SpA) and peripheral (p-SpA) spondyloarthritis were applied [17]. The first clinical evaluation data were considered to measure disease activity, functional impairment and structural damage measurements, including BASDAI (Bath Ankylosing Spondylitis Disease Activity Index) and ASDAS (Ankylosing Spondylitis Disease Activity Score), BASFI (Bath Ankylosing Spondylitis Functional Index), BASMI (Bath Ankylosing Spondylitis Metrology Index) and mSASSS (modified Stoke Ankylosing Spondylitis Spinal Score) [17].

Patients signed an Informed Consent Form, and the study was approved by the Ethics Committee of the Federal University of São Paulo (1478/09).

Numerical data were presented as the mean \pm standard deviation and categorical variables as percentages. P below 0.05 was set as significant. The Statistical Package for Social Science software (SPSS version 20.0) was used for descriptive analysis.

\section{Results}

The demographic and clinical manifestations of these nine patients are described in Table 1 . The mean weight loss after BP surgery was $49.3 \pm 21.9 \mathrm{~kg}$. The BS techniques were Roux-en-Y gastric bypass $(n=8 ; 88.9 \%)$ and biliopancreatic diversion with duodenal switch $(n=1$; $11.1 \%)$.

Four (44.4\%) patients had no axial or peripheral pain complaints before BS, while the other four (44.4\%) had sporadic non-inflammatory back pain that had been attributed to obesity. One patient (11.1\%) had persistent chronic back pain and had been submitted to surgery for spinal stenosis correction (L5-S1 segment). In all nine cases, patients reported back pain onset or pattern (from unspecified or non-inflammatory to IBP, according to the ASAS criteria) or intensity (from mild to moderate or severe) change after BS (mean time of $14.7 \pm 18.0$ months). In addition to axial manifestation, all of them had calcaneal enthesitis, and more than half had arthritis at the onset of symptoms. In addition, 8 of them (88.9\%) were human leukocyte antigen (HLA)-B27 positive.

Regarding extra-articular manifestations, one patient had recurrent anterior uveitis and IBP after 12 months of BS. Another patient had chronic non-specific colitis. One patient had psoriasis, and no cutaneous manifestation suggestive of BADAS was observed in any of them.

Five (55.6\%) patients were classified as AS, according to the $\mathrm{mNY}$ criteria. The plain pelvic radiograph demonstrated 
grade II bilateral sacroiliitis in four patients and grade III unilateral in one. The other four patients (44.4\%) were classified as non-radiographic axial SpA, according to the ASAS criteria (Table 1).

At the time of the first clinical evaluation, they had high disease activity according to BASDAI, ASDAS-CRP, with significant function and mobility impairment. After two years, the mSASSS data showed structural spine damage progression, defined as a new syndesmophyte, in 5 patients (Table 2).

Concerning treatment, all nine patients were taking nonsteroidal anti-inflammatory drugs on demand. Two (22.2\%) patients were taking methotrexate and two (22.2\%) were on sulfasalazine and other four (44.4\%) were taking anti-tumor necrosis factor agents. It was necessary to reverse the BS of one patient due to intensity and refractoriness of axial and peripheral SpA complaints. After that, he had significant clinical improvement but did not reach complete remission.

\section{Discussion}

This series of cases highlights the possible temporal link between the onset of symptoms related to SpA and the

Table 1 Clinical, demographic and imaging characteristics of patients with new onset axial Spondyloarthritis after bariatric surgery

\begin{tabular}{|c|c|}
\hline Patient characteristics $(n=9)$ & \\
\hline $\operatorname{Sex}(M: F)$ & $4: 5$ \\
\hline Current age (years) & $49.5 \pm 10.1$ \\
\hline Age at the onset of symptoms (years) & $42.0 \pm 9.1$ \\
\hline Disease duration (years) & $5.7 \pm 3.0$ \\
\hline Time between surgery and symptoms (months) & $14.7 \pm 18.0$ \\
\hline White color & $7(77.8 \%)$ \\
\hline HLA-B27 positive & $8(88.9 \%)$ \\
\hline Chronic low back pain (> 3 months) & $9(100 \%)$ \\
\hline Inflammatory low back pain & $7(77.8 \%)$ \\
\hline Arthritis & $5(55.6 \%)$ \\
\hline Calcaneal enthesitis & $9(100 \%)$ \\
\hline Dactylitis & $0(0 \%)$ \\
\hline Recurrent anterior uveitis & $3(33.3 \%)$ \\
\hline Colitis & $1(11.1 \%)$ \\
\hline Balanitis circinata/ urethritis & $0(0 \%)$ \\
\hline Psoriasis & $1(11.1 \%)$ \\
\hline $\begin{array}{l}\text { Radiographic evidence of sacroiliitis }(n=9) \\
\text { Grade II bilateral } \\
\text { Grade III unilateral or higher }\end{array}$ & $\begin{array}{l}5(55.6 \%) \\
4(80 \%) \\
1(20 \%)\end{array}$ \\
\hline Sacroiliac Joint MRI* $(n=4)$ & $4(100 \%)$ \\
\hline
\end{tabular}

Table 2 Assessment of disease activity and structural damage

\begin{tabular}{ll}
\hline Assessment of disease activity and structural damage $(\mathrm{n}=9)$ \\
\hline BASDAl & $5.0 \pm 1.4$ \\
ASDAS-ESR & $3.9 \pm 0.6$ \\
ASDAS-CRP & $3.2 \pm 1.2$ \\
BASFI & $3.7 \pm 2.4$ \\
BASMI & $3.6 \pm 1.7$ \\
ESR (mm/h) & $52.4 \pm 27.5$ \\
CRP(mg/L) & $11.7 \pm 16.8$ \\
mSASSS Cervical (0-36) ${ }^{\Delta}$ & $13 \pm 12.4(10)$ \\
mSASSS Lumbar (0-36) & $\Delta$ \\
mSASSS Total (0-72) &
\end{tabular}

Numeric variables expressed as mean \pm standard deviation. ${ }^{\triangle}$ Data presented as mean \pm standard deviation (median). BASDAl (Bath Ankylosing Spondylitis Disease Activity Index); BASFI (Bath Ankylosing Spondylitis Functional Index); $B A S M I$ (Bath Ankylosing Spondylitis Metrology Index); ASDAS (Ankylosing Spondylitis Disease Activity Score); ESR (erythrocyte sedimentation rate); CRP (C-reactive protein), mSASSS (modified Stoke Ankylosing Spondylitis Spinal Score)

BS, suggesting a possible causal plausibility between them. Although with a variable time interval, there was a clear temporal relationship between BS and the onset of axial and/or peripheral joint symptoms, as well as extra-articular manifestations in previously asymptomatic patients or patients with vague complaints, such as occasional non-inflammatory non-chronic back pain and that were attributed to overweight and physical inactivity. To the best of our best knowledge, this is the more consistent case series, including sampling and clinical characterization, showing axial SpA after BS with current surgical techniques. Previously, most of the case reports were from patients with arthritis or BADAS, especially after BS using an obsolete and disabsorptive techniques.

Our data suggest that there may be a link between the intestinal microbiome changes (dysbiosis), after BS, and the clinical manifestations related to SpA. Likely, these mechanisms could be associated with HLA-B27 regarding antigen presentation and other innate immunity ways. Recently, it was demonstrated that AS patients had qualitative differences in their intestinal microbiome, including a higher frequency of five families of bacteria (Lachnospiraceae, Ruminococcaceae, Rikenellaceae, Porphyromonadaceae, Bacteroidaceae) and reduction in the abundance of two others (Veilonellaceae and Prevotellaceae) [18]. Although some evidence has demonstrated the role of genetic factors on gut microbiome composition, it is believed that the interaction with the HLA-B27 plays a relevant role, especially by the mis-folding theory or formation of homodimers on the surface of antigen-presenting cells, leading to the induction of immunological pathways, such as IL-23/IL-17 axis. Furthermore, it was shown that there is a relationship between the presence of chronic ileocolic inflammation 
and increased inflammatory activity on SIJ MRI in patients with AS, emphasizing the close link between gut inflammation and the axial involvement [19].

Bacterial overgrowth induced by changes in peristalsis, drainage pathways and chemical composition of digestive juices, as well as $\mathrm{pH}$ elevation, could be an additional pathophysiological mechanism, but none of the patients showed any clinical evidence of these symptoms, including malaise, fever, hypoglycemia and stool bulk modifications. On the other hand, the dumping phenomenon was common to all.

Additionally, this setting could be the clinical translation of the HLA-B27 transgenic mice models that do not develop the symptoms of joint disease in a germ-free microenvironment [20]. The partial clinical and laboratory improvement of a patient following reversal of BS, as observed by other authors, reinforces this hypothesis [11].

All nine patients had heel pain at the time of first clinical evaluation. We did not perform any ultrasound or magnetic resonance imaging of this specific entheseal site, because calcaneal enthesopathy is common in obese individuals, and we cannot guarantee that it was associated with inflammatory SpA background or just related to overweight mechanical stress itself.

Considering the HLA-B27 has a crucial role in four theoretical models to explain the pathophysiological aspects related to articular and extra-articular manifestations in SpA experimental models, we could explore that SpA features after BS, where huge microbiota changes can occur, could be more frequent in HLA-B27 positive patients [21, 22]. Interestingly, none of the patients reported any family history of diseases related to the SpA concept. Thus, the HLA-B27 status definition could be to take account by surgeons and patients before making decision for BS choosing. Nonetheless, it is worthy emphasizing that more prospective studies with larger sampling are needed to establish the cause and effect relationship between both conditions.

Our study has some limitations, such as the retrospective design and problems inherent to remembering medical complaints, including dates and characteristics of pain and articular and extra-articular manifestations. Secondly, the intestinal microbiome was not evaluated. In contrast, it has other relevant aspects, such as the description of a case series and assessment and detailed characterization of patients over time, demonstrating the possible temporal link between BS and onset of SpA symptoms.

\section{Conclusion}

Our data showed SpA could arise after surgical interventions for obesity treatment, especially Roux-en-Y, in patients with genetic susceptibility conferred by the presence of HLA-B27.

\section{Acknowledgements}

To our study group of Spondyloarthritis.

Funding

This work has no funding to declare.

Availability of data and materials

All data and materials of this manuscript are available for consultation.

\section{Authors' contributions}

TLO did the clinical evaluations of patients and wrote the article; HTL revised the article and MMP idealized the project and did revision of the manuscript. All authors read and approved the final manuscript.

\section{Ethics approval and consent to participate}

Patients signed an Informed Consent Form, and the study was approved by the Ethics Committee of the Federal University of São Paulo (1478/09).

\section{Consent for publication}

Not applicable.

\section{Competing interests}

The authors declare that they have no competing interests.

\section{Publisher's Note}

Springer Nature remains neutral with regard to jurisdictional claims in published maps and institutional affiliations.

\section{Author details}

${ }^{1}$ Rheumatology Division, Spondyloarthritis Section, Universidade Federal de São Paulo, Rua Leandro Dupré, 204, Conjunto 74, Vila Clementino, São Paulo, SP CEP 04025-010, Brazil. ²Hospital Israelita Albert Einstein, São Paulo, Brazil.

Received: 24 August 2018 Accepted: 30 January 2019

Published online: 14 February 2019

References

1. Fruhbeck G. Bariatric and metabolic surgery: a shift in eligibility and success criteria. Nat Rev Endocrinol. 2015;11(8):465-77. https://doi.org/10.1038/ nrendo.2015.84.

2. Pories WJ. Bariatric surgery: risks and rewards. J Clin Endocrinol Metab. 2008; 93(11 Suppl 1):S89-96. https://doi.org/10.1210/jc.2008-1641.

3. Drenick EJ, Ament ME, Finegold SM, Corrodi P, Passaro E. Bypass enteropathy. Intestinal and systemic manifestations following small-bowel bypass. JAMA. 1976;236(3):269-72. https://doi.org/10.1001/jama.1976. 03270030023022.

4. Gamble CN, Kimchi A, Depner TA, Christensen D. Immune complex glomerulonephritis and dermal vasculitis following intestinal bypass for morbid obesity. Am J Clin Pathol. 1982;77(3):347-52. https://doi.org/10.1093/ ajcp/77.3.347.

5. Zapanta M, Aldo-Benson M, Biegel A, Madura J. Arthritis associated with jejunoileal bypass. clinical and immunologic evaluation Arthritis Rheum. 1979:22(7):711-7. https://doi.org/10.1002/art.1780220704.

6. Dicken CH, Seehafer JR. Bowel bypass syndrome. Arch Dermatol. 1979; 115(7):837-9. https://doi.org/10.1001/archderm.1979.04010070013012.

7. Stein HB, Schlappner OL, Boyko W, Gourlay RH, Reeve CE. The intestinal bypass: arthritis-dermatitis syndrome. Arthritis Rheum. 1981;24(5):684-90. https://doi.org/10.1002/art.1780240509.

8. Tu J, Chan JJ, Yu LL. Bowel bypass syndrome/bowel-associated dermatosis arthritis syndrome post laparoscopic gastric bypass surgery. Australas J Dermatol. 2011;52(1):e5-7. https://doi.org/10.1111/j.1440-0960.2009.00614.x.

9. Slater GH, Kerlin P, Georghiou PR, Fielding GA. Bowel-associated dermatosis-arthritis syndrome after biliopancreatic diversion. Obes Surg. 2004;14(1):133-5. https://doi.org/10.1381/096089204772787446.

10. Le Quintrec JL, Puechal X, Marin A, Lamy P, Gendre JP, Menkes CJ. Chronic erosive arthritis associated with an unusual intestinal bypass. Clin Exp Rheumatol. 1991;9(5):529-32. 
11. Kudo H. A case of chronic erosive polyarthirits which developed 14 years after an intestinal bypass operation with subsequent remission by intestinal revision. Ryumachi. 2001;41(5):880-7.

12. Ribeiro DS, Fernandes JL, Rangel L, de Araújo Neto C, D'Almeida F, Moura CG, et al. Spondyloarthritis after bariatric surgery: is there a link? Clin Rheumatol. 2010;29(4):435-7. https://doi.org/10.1007/s10067-009-1351-4.

13. Rose E, Espinoza LR, Osterland CK. Intestinal bypass arthritis: association with circulating immune complexes and HLA B27. J Rheumatol. 1977:4(2):129-34

14. Corcelles R, Daigle CR, Talamas HR, Batayyah E, Brethauer SA, Schauer PR. Bariatric surgery outcomes in patients with systemic lupus erythematosus. Surg Obes Relat Dis. 2015;11(3):684-8. https://doi.org/10. 1016/j.soard.2014.10.006

15. Sparks JA, Halperin F, Karlson JC, Karlson EW, Bermas BL. Impact of bariatric surgery on patients with rheumatoid arthritis. Arthritis Care Res (Hoboken). 2015:67(12):1619-26. https://doi.org/10.1002/acr.22629.

16. Carubbi F, Ruscitti P, Pantano I, Alvaro S, Benedetto PD, Liakouli V, et al. Jejunoileal bypass as the main procedure in the onset of immune-related conditions: the model of BADAS. Expert Rev Clin Immunol. 2013;9(5):441-52.

17. Sieper J, Rudwaleit M, Baraliakos X, Brandt J, Burgos-Vargas R, Dougados M, et al. The assessment of Spondyloarthritis international society (ASAS) handbook: a guide to assess spondyloarthritis. Ann Rheum Dis. 2009;68:1-44.

18. Costello M-E, Ciccia F, Willner D, Warrington N, Robinson PC, Gardiner B, et al. Brief report: intestinal dysbiosis in ankylosing spondylitis. Arthritis Rheumatol. 2015;67(3):686-91. https://doi.org/10.1002/art.38967.

19. Van Praet L, Jans L, Carron P, Jacques P, Glorieus E, Colman R, et al. Degree of bone marrow oedema in sacroiliac joints of patients with axial spondyloarthritis is linked to gut inflammation and male sex: results from the GIANT cohort. Ann Rheum Dis. 2014;73:1186-9. https://doi.org/10.1136/ annrheumdis-2013-203854.

20. Rath H, Herfarth H, Ikeda J, Grenther WB, Hamm TE Jr, Balish E, et al. Normal luminal bacteria, especially bacteroides species, mediate chronic colitis, gastritis, and arthritis in HLA-B27/human beta2 microglobulin transgenic rats. J Clin Invest. 1996;98:945-53. https://doi.org/10.1172/JCl118878.

21. Lin $P$, Bach M, Asquith M, Lee AY, Akileswaran L, Stauffer P, et al. HLA-B27 and human $\beta 2$-microglobulin affect the gut microbiota of transgenic rats. PLoS One. 2014;9(8):e105684. https://doi.org/10.1371/journal.pone.0105684.

22. Asquith M, Brooks SR, Rosenbaum JT, Colbert RA. Effects of HLA-B27 on gut microbiota in experimental Spondyloarthritis implicate an ecological model of Dysbiosis. Arthritis Rheumatol. 2018;70(4):555-65.

Ready to submit your research? Choose BMC and benefit from:

- fast, convenient online submission

- thorough peer review by experienced researchers in your field

- rapid publication on acceptance

- support for research data, including large and complex data types

- gold Open Access which fosters wider collaboration and increased citations

- maximum visibility for your research: over $100 \mathrm{M}$ website views per year

At $\mathrm{BMC}$, research is always in progress.

Learn more biomedcentral.com/submissions 